\title{
Orthopraxy, not orthodoxy
}

doi:10.1136/flgastro-2017-100937

This edition represents the first edition of the ninth year of Frontline Gastroenterology. We are delighted to have seen the journal become an established fixture in the wide field of GI publications. We hope all previous submitting authors have been equally pleased to have received notification that their manuscripts are now findable on PubMed, and the editorial board look forward to establishing an impact factor as the next stage of the journal's development. We intend to maintain and enhance the journal's key selling point, namely being a journal that clinicians turn to for evidence of what is contemporary in best practice. This often means challenging the rituals and orthodox beliefs of what is 'accepted' and undertaking changes in practice that help improve care of GI patients - this edition of the journal highlights just such manuscripts.

\section{Gastric biopsies in the dyspeptic patient: challenging the orthodoxy}

The editor's choice in this edition is a paper by Gibson et $a l^{1}$ from Newcastle, addressing this important issue of the role of gastric biopsies in the management of patients who undergo an upper gastrointestinal biopsy for investigation of dyspepsia or reflux. The inclination to 'just take a sample while you're down there' is commonly indulged, despite evidence that it does not usefully or cost-effectively contribute to detection of gastric cancer or presence of Helicobacter pylori. The authors developed a 'when to biopsy' protocol and educated colleagues, followed by an analysis of the impact of the intervention. To find out the result of the intervention, we encourage you to read the paper, and in so doing there will be exposure to the methodology of undertaking such a collaborative educational approach, as well as the opportunity to understand (and, possibly, locally adapt) the protocol.

Whether the gastroscopy needs to be undertaken in the first place is a question addressed in the paper by Ching and colleagues $^{2}$ from Sheffield. The observations provide a powerful argument for commissioners and providers of endoscopy to reduce the ritualised pathway of

\section{Anton V Emmanuel}

referring over 55 year olds with dyspepsia. The paper corroborates the biopsy findings of the Newcastle paper but also identifies that a minority percentage of patients have management influenced by the procedure - before reading the paper it may be an interesting exercise for the reader to speculate what that percentage may be, and see if they are correct.

\section{Chronic vomiting: what is, and is not, cyclical vomiting?}

Patients presenting with recurrent vomiting in the absence of a structural abnormality represent a group of patients who are often very difficult to manage. The paucity of effective - and safe - medications for such chronic symptoms make this among the most challenging of neurogastroenterology patients to manage. Cyclical vomiting syndrome (CVS) is a relatively rare cause of this presentation: however, rather like the use of the term migraine to describe all headache, patients (and physicians) often feel this is the diagnosis. The Northern powerhouse of UK gastroenterology is complemented by the case report and literature review by Shearer $\mathrm{et}_{\mathrm{al}}^{3}$ in Leeds, of this intermittent condition. The article will prove useful to gastroenterologist by detailing the aspects of meticulous history taking (to identify the natural history and relieving factors of the vomiting) that go towards making a diagnosis, as well as reviewing the management options for each phase of the condition.

\section{Contemporary management of hepatitis B}

With the major treatment-induced changes in the natural history of hepatitis $\mathrm{C}$ infection it is important to remember that 1 in 50 Europeans and 1 in 200 of the UK population will have chronic hepatitis B infection. As novel therapeutic agents for the treatment of chronic hepatitis B infection are developed which not only are able to sustainably suppress viral DNA but also aim to achieve functional cure, it is timely to review what is the current gold standard of therapy. Wang and colleagues ${ }^{4}$ at King's College London provide this in the current edition of Frontline Gastroenterology, detailing not just the evidence of efficacy for the available agents, but also a pragmatic approach to monitoring for complications and managing episodes of decompensation. Despite this, liver transplantation is needed in some patients, complicated by the potential re-infection of the graft: the paper also describes the potential prophylaxis of such re-infection, and proposes an algorithm for risk-stratification of such management.

\section{Do NSAIDs reduce post-ERCP pancreatitis? Real life evidence}

There are scenarios when guidance is developed based on 'common sense' and limited clinical evidence. One such is the recommendation of expert USA and European endoscopy societies in favour if the use of non steroidals as prophylaxis of pancreatitis complicating ERCP. Sheiybani et $a l^{5}$ report on 1318 ERCP procedures comparing the incidence of this complication before and after introduction of rectal diclofenac. Their data look at the use of the drug both in selected high risk individuals as well as all-comers, and they provide invaluable evidence to support the published guidance - orthopraxy to support the orthodoxy.

\section{REFERENCES}

1 Gibson V, Needham S, Nayer M, et al. Do non-targeted gastric biopsies affect the management of patients, and can a simple protocol and education reduce the rate?. Frontline Gastroenterology 2018;9:67-72.

2 Ching H-L, Hale MF, Sidhu R, et al. Reassessing the value of gastroscopy for the investigation of dyspepsia. Frontline Gastroenterology 2018;9:62-6.

3 Shearer J, Luthra P, Ford AC. Cyclic vomiting syndrome: a case series and review of the literature. Frontline Gastroenterology 2018;9:2-9.

4 Wang B, Agarwal K, Joshi D. Management of chronic hepatitis B before and after liver transplantation. Frontline Gastroenterology 2018;9:79-84.

5 Sheiybani G, Brydon P, Toolan M. Does rectal diclofenac reduce post- ERCP pancreatitis? A district general hospital experience. Frontline Gastroenterology 2018;9:73-7. 